\section{EL ARBITRAJE EN LOS GRUPOS DE EMPRESAS FAMILIARES}

\author{
THE ARBITRATION IN THE \\ FAMILY BUSINESS GROUPS
}

\section{Daniel Echaiz Moreno}

\section{RESUMEN}

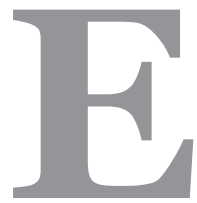

ste trabajo gira en torno a tres instituciones contemporáneas del Derecho Mercantil que aquí se entrelaza, a la luz de lo que sucedió recientemente en la realidad del mercado; nos referimos a los grupos de empresas, las empresas familiares y el arbitraje comercial. Sucede que hoy en día puede apreciarse con frecuencia regular que las empresas no suelen actuar, sino que lo hacen formando grupos de empresas donde distinguimos la matriz (que actúa como tenencia) y las subsidiarias (que, a veces, son matrices de otras filiales). Por otro lado, muchas de esas empresas son familiares, debiendo marcarse distancia entre la empresa familiar y la familia empresarial para el adecuado funcionamiento de aquella. Finalmente, el arbitraje comercial ha ganado terreno para la resolución de las controversias atinentes a las empresas, incluso incorporándose estatutariamente y siendo de especial interés a los grupos de empresas y las empresas familiares. De todo esto resulta que hay veces en que los grupos de empresas son grupos de empresas familiares y en ellos se establece el arbitraje comercial como mecanismo para la solución de conflictos, aterrizando así en el tema del presente trabajo: el arbitraje en los grupos de empresas familiares.

Palabras clave: arbitraje, empresas familiares, grupos de empresas.

\section{ABSTRACT}

This work revolves around three contemporary institutions of Commercial Law that we intertwine here, in the light of what precisely happens in the reality of the market; we refer to business groups, family businesses and commercial arbitration. It happens that nowadays it can be
Daniel Echaiz Moreno daniel@echaiz.com

Universidad Peruana de Ciencias Aplicadas (UPC)

Miembro de Laureate International Universities PERÚ 


\begin{tabular}{c}
\hline $30<$ \\
ELHAIZ MORENO, DANIEL \\
EL ARBITRAJE EN LOS GRUPOS DE EMPRESAS FAMILIARES. \\
Págs. $29-41$. DOI: $h t t p: / / d x$. doi.org/10.30972/rfce.2213947
\end{tabular}

seen with regular frequency that companies do not usually act in isolation, but they do so by forming groups of companies where we distinguish the parent company (which acts as a holding company) and the subsidiaries (which are sometimes matrices of other subsidiaries). On the other hand, many of these companies are family, and the distance between the family business and the business family must be marked for the proper functioning of the business. Finally, commercial arbitration has gained ground for the resolution of disputes concerning companies, including by statutory incorporation and being of special interest to business groups and family businesses. It follows that there are times when business groups are family business groups and they establish commercial arbitration as a mechanism for conflict resolution, thus landing on the subject of this paper: arbitration in business groups family members.

Keywords: arbitration, family businesses, business groups.

\section{INTRODUCCIÓN}

El propósito del presente trabajo es analizar la funcionalidad que tiene el arbitraje como mecanismo de resolución de controversias, alterno a la tradicional vía judicial, en los grupos de empresas familiares. Asumimos dicha tarea a propósito de nuestra experiencia profesional como árbitro (adscrito a diversos Centros de Arbitraje), especialista en grupos de empresas (desde nuestra tesis para optar el título de abogado) e investigador académico en materia de empresas familiares (en el Instituto Argentino de la Empresa Familiar).

Precisamente este trabajo gira en torno a tres instituciones contemporáneas del Derecho Mercantil que aquí entrelazamos, a la luz de lo que precisamente acontece en la realidad del mercado; nos referimos a los grupos de empresas, las empresas familiares y el arbitraje comercial.

a) Sucede que hoy en día puede apreciarse con regular frecuencia que las empresas no suelen actuar aisladas, sino que lo hacen formando grupos de empresas donde distinguimos la matriz (que actúa como holding) y las subsidiarias (que, a veces, son matrices de otras filiales).

b) Por otro lado, muchas de esas empresas son familiares, debiendo marcarse distancia entre la empresa familiar y la familia empresaria para el adecuado funcionamiento de aquella.

c) Finalmente, el arbitraje comercial ha ganado terreno para la resolución de las controversias atinentes a las empresas, incluso incorporándose estatutariamente y siendo de especial interés a los grupos de empresas y a las empresas familiares. 
De todo ello resulta que hay veces en que los grupos de empresas son grupos de empresas familiares y en ellos se establece el arbitraje comercial como mecanismo para la solución de conflictos, aterrizando así en el tema del presente trabajo: el arbitraje en los grupos de empresas familiares.

Si bien nuestro análisis se ubica en el contexto jurídico, social y económico del Perú, no somos ajenos al desenvolvimiento de las referidas instituciones en la experiencia internacional, por lo que pretendemos atender a su desarrollo en otros países para reflexionar qué cuestiones serían oportunas considerar en nuestro país.

\section{MARCO CONCEPTUAL}

Las tres instituciones anteriormente aludidas no son ajenas a nuestra experiencia profesional y académica, por lo que el marco conceptual básico de cada una de ellas lo haremos a propósito de nuestras publicaciones en la materia.

\subsection{El arbitraje}

En el 2007 publicamos un artículo en Colombia, el cual comenzaba así:

"En el hotel Marriott Marquis, de Nueva York, sus 16 ascensores no tienen botones. A la vez, las dos mil personas que diariamente los usan han visto reducido el tiempo de espera de 90 a 20 segundos, aunque algunos sienten claustrofobia. Se trata de los ascensores de destino, comercializados por las gigantes Otis Elevator y Schindler Holding, donde debe ingresarse previamente el número del piso deseado en un tablero que indica cuál elevador está disponible.

El arbitraje también carece de botones que permitan detenerlo, pues cuando empieza su marcha no tolera ni siquiera la intromisión judicial (¿y la anulación del laudo arbitral?: recién cuando concluye el arbitraje). La reducción del tiempo en la solución de las controversias lo justifica, ya que, a diferencia de la excesiva carga procesal de los jueces, los tribunales arbitrales se constituyen para cada caso. No hay que sentir claustrofobia; sólo supone acostumbrarse a un nuevo modelo de ascensor". ${ }^{1}$

En efecto, el arbitraje se ubica dentro de la categoría de los mecanismos alternativos de resolución de conflictos (conocidos por sus siglas: MARC's) y supone sustraerse de la competencia judicial; el arbitraje equivale al proceso judicial, el árbitro equivale al juez y el laudo arbitral equivale a la sentencia. Las innumerables ventajas que ofrece el arbitraje se aprecian con mayor atractivo en el mundo de los negocios donde la rapidez en la toma de decisiones, la confiabilidad en los pronunciamientos de la autoridad y la especialización en los asuntos corporativos hacen

${ }^{1}$ Cfr. Echaiz Moreno, Daniel. "Los ascensores sin botones: una nueva manera de comprender el arbitraje”. En: Portal Arbitraje Comercial Internacional. Bogotá, Editorial Legis Colombia, 15 de marzo del 2007. 
del arbitraje una herramienta eficiente y eficaz en el mercado. Como bien señala Guillermo Lohmann, "la naturaleza y especialidad de los conflictos no permiten su conocimiento y adecuada resolución por los organismos judiciales con la rapidez que conviene a las cosas” ${ }^{2}$; sin embargo, “(...) aún su ejercicio se mantiene reservado a las grandes empresas y no ha logrado ser asimilado por la mayoría empresarial de nuestro país, compuesta básicamente por medianas y pequeñas empresas que diariamente ventilan sus conflictos en la vía judicial”. ${ }^{3}$

\subsection{Los grupos de empresas}

A los grupos de empresas le hemos dedicado varias de nuestras obras y ahora citamos una publicada en Alemania en la cual los definimos como "un fenómeno derivado de la concentración empresarial, de naturaleza multiarticulada, constituido por dos o más empresas jurídicamente autónomas, en el cual existe una dirección unificada destinada a la satisfacción del interés grupal y para lo cual se establecen relaciones de dominación-dependencia, las que importan el control ejercido por uno o varios sujetos dominantes (pudiendo ser alguna de las empresas) sobre la empresa o empresas dominadas". ${ }^{4}$

El punto de partida es la concentración empresarial. Aquí puede optarse por perder la personalidad jurídica o no de las empresas participantes: en el primer caso estamos ante las fusiones y, en el segundo, ante las uniones de empresas. En estas últimas se podrán establecer relaciones de coordinación o relaciones de subordinación: las primeras se ejemplifican con el consorcio, la asociación en participación, el pool aeronáutico, etc., mientras que las segundas se manifiestan a través del grupo de empresas.

Las características estructurales de los grupos de empresas son la autonomía jurídica de las empresas participantes, de modo tal que cada una de ellas es una persona jurídica que califica como sujeto de derecho; la relación de dominación-dependencia que, jerárquicamente, se establece entre la matriz y las filiales; y la dirección unificada que supone la satisfacción del interés grupal, siendo ejercida por el sujeto dominante, el cual puede ser una persona natural, un conjunto de personas naturales (como una familia empresaria) o una persona jurídica (usualmente, una holding e, incluso, una off-shore).

\subsection{Las empresas familiares}

En el 2010, en México, se publicó nuestra investigación jurídica sobre el protocolo familiar y ahí conceptualizamos a las empresas familiares en los siguientes términos: “[es] aquella

\footnotetext{
2 Lohmann Luca de Tena, Guillermo. "El Arbitraje en el Perú". En: Revista Jus Doctrina \& Práctica. Lima, Editora Jurídica Grijley, 2007, № 5, p.19.

${ }^{3}$ Cfr. Valdivieso López, Erika. "La solución de conflictos societarios en la jurisdicción arbitral”. En: Revista Actualidad Jurídica. Lima, Editorial Gaceta Jurídica, 2010, № 203, ps. 269 y 270.

${ }^{4}$ Cfr. Echaiz Moreno, Daniel. Derecho \& Empresa. Bases para la moderna concepción del Derecho Empresarial. Berlín, LAP LAMBERT Academic Publishing a través de Editorial Académica Española, octubre del 2011, p. 112.
} 
organización de carácter económico cuyo objeto principal sea la producción o comercialización de bienes o la prestación de servicios, cuya propiedad pertenece, en su totalidad o en una mayoría, a un grupo de personas unidas por un vínculo familiar, habitualmente los descendientes del fundador de la misma. Otros factores que suelen tenerse en cuenta a la hora de valorar si una empresa es o no familiar es que la mayoría de los órganos de administración y control sean nombrados por un grupo familiar o que algún miembro de la familia participe en dichos órganos". ${ }^{5}$

Cabe pues una diferenciación conceptual: se considera "empresa familiar" a aquella empresa cuya administración y propiedad está en poder de una o más familias, mientras que la "familia empresaria" corresponde a un equipo de personas, con vínculos familiares entre ellos, que promueven la implantación de "buenas prácticas" y el desarrollo de las ventajas competitivas en los negocios de los cuales son propietarios, entendiendo que estas empresas son y/o serán fuente de generación de valor para ellas.

El abanico de ventajas de una empresa familiar por ser precisamente familiar es amplio. "Va desde el compromiso con el negocio hasta la expectativa de inversión a largo plazo, pasando por la estabilidad laboral, la cohesión del equipo directivo y la plana gerencial, el conocimiento del mercado, la facilidad de adaptación a los cambios y la capacidad de autofinanciación. Pero todas estas ventajas pueden significar, a su vez, sus potenciales debilidades. Por ejemplo, identificar a una familia con un negocio (como Azcárraga con los medios de comunicación en México o Luksic con la minería en Chile) podría ser un obstáculo para cambiar de sector económico; sólo algunos lo hacen con éxito, como la familia Wiese que pasó de la banca al negocio inmobiliario". ${ }^{6}$

La trascendencia de las empresas familiares es evidente: se calcula que representan el 66\% en el mundo, el 75\% en la Unión Europea, el 80\% en México, el 85\% en Estados Unidos, el 90\% en Chile y el 95\% en Italia, por citar algunos casos. Son empresas familiares el Grupo Barone Ricasoli (de Italia), en actividad desde el año 1141; Faber-Castell (de Alemania), que ya va por su octava generación; y Wal-Mart (de Estados Unidos), que es la mayor cadena minorista del mundo. En el Perú los grupos empresariales más importantes son familiares, tales como Credicorp (Romero), Breca (Brescia), Buenaventura (Benavides de la Quintana), Intercorp (Rodríguez Pastor) y Gloria (Rodríguez Banda).

\footnotetext{
${ }^{5}$ Cfr. Echaiz Moreno, Daniel. "El protocolo familiar. La contractualización en las familias empresarias para la gestión de las empresas familiares". En: Boletín Mexicano de Derecho Comparado. México, Instituto de Investigaciones Jurídicas de la Universidad Nacional Autónoma de México, enero-abril del 2010, Año XLIII, N 127, p. 110. ${ }^{3}$ Cfr. Valdivieso López, Erika. "La solución de conflictos societarios en la jurisdicción arbitral”. En: Revista Actualidad Jurídica. Lima, Editorial Gaceta Jurídica, 2010, № 203, ps. 269 y 270. ${ }^{6}$ Cfr. "Importancia de las empresas familiares" (entrevista a Daniel Echaiz Moreno). En: Suplemento Jurídica. Lima, Diario Oficial El Peruano, 2 de agosto del 2011, p. 4.
} 


\section{LA DINÁMICA FUNCIONAL EN LOS GRUPOS DE EMPRESAS FAMILIARES}

Si bien, el éxito de una empresa se analiza frecuentemente desde el punto de vista financiero, en el caso de la empresa familiar, lo realmente importante es proteger la interrelación entre la familia y la empresa. En razón a ello y a fin de garantizar el futuro de ambas, no sólo será relevante el rendimiento económico sino también que la familia se mantenga unida y comprometida con la empresa a través de los años, lo que podría ser llamado "rendimiento familiar", siendo esta característica la que hará la diferencia entre una empresa familiar exitosa y una condenada a fracasar. ${ }^{7}$

Por ello, todas las empresas familiares que han logrado incrementar el valor de éstas a través del tiempo suelen contar con políticas claras para regular la relación entre los familiares y la compañía, definiendo la misión y la visión tanto para la familia como para la dirección de la empresa, así como las responsabilidades de los parientes con respecto a esta última. ${ }^{8}$

Es dentro de ese contexto donde se vislumbra mejor la funcionalidad del protocolo familiar, cuya razón de ser es, justamente, constituir un instrumento regulador de las relaciones familiares y empresariales, esto es, el soporte donde se establecerán las normas de conducta que cada integrante del binomio familia-empresa deberá cumplir, a fin de facilitar la prevención y solución de los conflictos que pudieran suscitarse al interior de la empresa familiar.

En este orden de ideas, el protocolo familiar (equivalente al shareholders agreement de la close corporation en los Estados Unidos de América) constituye un acuerdo entre accionistas-familiares, quienes son titulares de bienes y derechos que desean gestionar unitariamente y preservar a largo plazo, regulando así, de manera conjunta, tanto la organización corporativa como las relaciones familiares inherentes a la empresa familiar. ${ }^{9}$

El protocolo familiar regulará principalmente aspectos como la sucesión, el reparto de dividendos y el trabajo de los familiares en la empresa, entre otros ${ }^{10}$. Asimismo, se establecen las fórmulas de mediación y/o arbitraje que se consideren necesarias para resolver futuros conflictos familiares que desencadenan consecuencias en la empresa familiar, pudiendo entonces fijarse la institución arbitral, el número de árbitros, etc. ${ }^{11}$. Dicho protocolo deberá tener una naturaleza abierta que le permite aplicar la consigna "adoptar-adaptar": adoptar nuevos conceptos para adaptarse al cambio, a fin de favorecer y facilitar la profesionalización de la empresa familiar dentro de un contexto de corporate governance, el cual posibilita que la empresa, aun siendo familiar, trascienda a sus titulares. ${ }^{12}$

\footnotetext{
7 "La microempresa: una propuesta tipológica y ejercicio de aplicación en Lima Sur". En: Boletín de Economía Laboral. Lima, Ministerio de Trabajo y Promoción del Empleo, 2006, Año 9, № 34, p. 23.

${ }^{8}$ Arrieta, Dolores. "Empresas familiares: cuando Ilegan los terceros". En: Revista de la Universidad Austral. Buenos Aires, IAE Business School, p. 71.

${ }^{9}$ Vicent Chuliá, Francisco. “Organización jurídica de la sociedad familiar”. En: Revista de Derecho Patrimonial. Navarra, Editorial Aranzadi, 2000, № 5, p. 38

${ }^{10}$ Ferré, Miguel; y Solano, Guillermo. Familia empresaria vs. empresa familiar, p. 9.

${ }^{11}$ Domínguez Martínez, Pilar. "El arbitraje societario como medio de resolución de conflictos en la empresa familiar". Documento de Trabajo № 2009/11, Seminario Permanente de Ciencias Sociales de la Universidad de Castilla, La Mancha, p. 13.

${ }^{12}$ Echaiz Moreno, Daniel. "El protocolo familiar como instrumento de gestión de las empresas familiares". En: Instituciones de Derecho Empresarial. Lima, Asociación Peruana de Ciencias Jurídicas y Conciliación (APECC), 2010, ps. 565 y 566.
} 
Sin embargo, a pesar de la utilidad del protocolo familiar en la resolución de conflictos, será el estatuto social de la empresa familiar el instrumento verdaderamente efectivo en la prevención y resolución de conflictos, debido principalmente a su carácter vinculante ${ }^{13}$. Es en virtud a ello que la elaboración del protocolo familiar de una familia empresaria va de la mano con un conveniente asesoramiento jurídico que ayudará a que lo expresado en dicho documento tenga poder vinculante a través de su incorporación al estatuto social y la celebración de acuerdos parasocietarios, entre otros mecanismos ${ }^{14}$.

\section{EL ARBITRAJE SOCIETARIO}

El arbitraje societario también es denominado arbitraje estatutario, en virtud que el convenio arbitral en el caso de las sociedades es incluido, casi siempre, a través de una cláusula en el estatuto social. ${ }^{15}$

"Los expertos aconsejan a las compañías incluir en sus estatutos sociales una cláusula de arbitraje que permita acudir de inmediato a este sistema cuando surjan conflictos societarios entre la sociedad y los socios, o entre los administradores y los socios, así como la posibilidad de someter a arbitraje la impugnación de los acuerdos sociales que ha sido objeto de debate jurisprudencial y doctrinal, así como conflictos societarios entre la empresa, los accionistas, los acreedores y los auditores, o entre cualquiera de los anteriores"16 (El resaltado es nuestro). Todo ello a fin de evitar las complicaciones que acarrea el someterse a la vía judicial para buscar resolver las controversias que surgen al interior de una empresa familiar, tales como la demora en resolver el conflicto, la falta de predictibilidad en las decisiones judiciales, la exigua especialización de los magistrados, etc.

\subsection{El arbitraje societario en el Perú}

El 27 de junio del 2008 se aprobó mediante el Decreto Legislativo $\mathrm{N}^{0} 1071$ la nueva Ley de Arbitraje, la cual nace como parte del paquete de medidas legislativas que el Estado peruano adoptó para implementar el Acuerdo de Promoción Comercial que celebró con Estados Unidos de América, más conocido como el Tratado de Libre Comercio (TLC) PerúEstados Unidos.

En dicha ley, específicamente en su sexta disposición complementaria, se estipula, bajo el rotulo de "Arbitraje estatutario":

\footnotetext{
${ }^{13}$ Domínguez Martínez, Pilar. "El arbitraje societario como medio de resolución de conflictos en la empresa familiar", obra citada, p. 14.

${ }^{14}$ Ferré, Miguel; y Solano, Guillermo. Familia empresaria vs. empresa familiar, obra citada.

${ }^{15}$ Valdivieso López, Erika. "La solución de conflictos societarios en la jurisdicción arbitral”, obra citada, p. 273.

${ }^{16}$ Domínguez Martínez, Pilar. "El arbitraje societario como medio de resolución de conflictos en la empresa familiar", obra citada, p. 12.
} 
"Puede adoptarse un convenio arbitral en el estatuto de una persona jurídica para resolver las controversias entre la persona jurídica y sus miembros, directivos, administradores, representantes y funcionarios o las que surjan entre ellos respecto de sus derechos $u$ obligaciones o las relativas al cumplimiento de los estatutos o la validez de los acuerdos.

El convenio arbitral alcanza a todos los miembros, directivos, administradores, representantes y funcionarios que se incorporen a la sociedad, así como a aquellos que al momento de suscitarse la controversia hubiesen dejado de serlo.

El convenio arbitral no alcanza a las convocatorias a juntas, asambleas y consejos o cuando se requiera una autorización que exija la intervención del Ministerio Público”. (El resaltado es nuestro).

Similar redacción se encuentra recogida en el artículo 48 de nuestra Ley General de Sociedades, aprobada mediante Ley $\mathrm{N}^{\circ} 26887$, en donde se establece que:

"Los socios o accionistas pueden en el pacto o en el estatuto social adoptar un convenio arbitral para resolver las controversias que pudiera tener la sociedad con sus socios, accionistas, directivos, administradores y representantes, las que surjan entre ellos respecto de sus derechos u obligaciones, las relativas al cumplimiento de los estatutos o la validez de los acuerdos y para cualquier otra situación prevista en esta ley.

El convenio arbitral alcanza a los socios, accionistas, directivos, administradores y representantes que se incorporen a la sociedad, así como aquellos que al momento de suscitarse la controversia hubiesen dejado de serlo.

El convenio arbitral no alcanza a las convocatorias a juntas de accionistas o socios.

El pacto o estatuto social puede también contemplar un procedimiento de conciliación para resolver la controversia con arreglo a la ley de la materia”. (El resaltado es nuestro).

De lo citado previamente se puede colegir que pactar un convenio arbitral no constituye una obligación sino una potestad que tienen los fundadores y/o socios de una empresa, a fin de someter sus potenciales controversias a la jurisdicción arbitral. Asimismo, queda claro que dicho convenio podrá ser incluido como una cláusula tanto en el pacto social como en el estatuto social.

Respecto al convenio arbitral podemos sostener que este constituye, principalmente, un acuerdo, en virtud del cual, las partes que lo celebran, deciden someter a arbitraje todas las controversias o ciertas controversias que hayan surgido o puedan surgir entre ellas respecto de una determinada relación jurídica contractual o de otra naturaleza, a la luz de lo dispuesto en el artículo 13 inciso 1 de la Ley de Arbitraje. Dicho convenio deberá constar por escrito, pudiendo adoptar la forma de una cláusula incluida en un contrato o la forma de un acuerdo independiente, en atención a lo prescrito en el artículo 13 inciso 2 de la misma norma arbitral.

Bajo este orden de ideas, el convenio arbitral en un grupo de empresas familiares podrá tener la forma de una cláusula estatutaria incorporada en el estatuto social de cada una de las empresas familiares miembro del grupo empresarial, sin perjuicio que exista un protocolo familiar general aplicable a todas las empresas que pertenecen a dicho grupo empresarial. 
Ello debido a que cada una de las empresas constituye una persona jurídica independiente, no siendo pues suficiente que el convenio arbitral estuviera estipulado sólo en el estatuto social de la empresa dominante.

Por lo demás, el artículo 55 de la Ley General de Sociedades estipula que el estatuto puede contener, además de las disposiciones señaladas en dicho artículo, "cualquier disposición lícita que los accionistas estimen conveniente para la organización de la sociedad”, lo cual facultaría a la sociedad a pactar la inclusión de una cláusula arbitral, disponiéndose obligatoriamente que los conflictos que surjan, ya sean de carácter externo (con los proveedores, los clientes o el Estado) o internos (con los accionistas, los fundadores o los administradores) se deban resolver a través del procedimiento arbitral.

La incorporación de la cláusula arbitral en el estatuto social es incluso reconocida en nuestra jurisprudencia como se evidencia en el Expediente $\mathrm{N}^{\circ} 72-98$, Sala $\mathrm{N}^{\circ} 3$ de Lima, en donde se señala: "Debe ampararse la excepción de convenio arbitral si en los estatutos de la empresa demandada se ha establecido que toda clase de controversias o desacuerdos entre accionistas y la sociedad deben de ser sometidos a la decisión inapelable de un tribunal arbitral".

Se ha discutido si es que, en razón a la naturaleza contractual del arbitraje (plasmada en el convenio arbitral que se incorpora al estatuto social), éste puede extenderse a quienes no participaron en su dación, como por ejemplo sucedería con los nuevos socios. Los defensores de la teoría contractual rechazan la extensión en su aplicación, pero frente a ellos se erige la teoría publicista según la cual el convenio arbitral es público desde que se incorpora al estatuto social y éste se encuentra inscrito ante los Registros Públicos, de modo que el nuevo socio estaba en posibilidades de conocerlo y, por consiguiente, asume las reglas de juego de la sociedad a la cual se incorpora. Por lo demás, el artículo 2012 del Código Civil recoge la presunción de publicidad registral, de naturaleza iure et de iure: "Se presume, sin admitirse prueba en contrario, que toda persona tiene conocimiento de las inscripciones".

Para zanjar esta discusión, el artículo 48 de la Ley General de Sociedades, anteriormente citado, prevé en su segundo párrafo: "El convenio arbitral alcanza a los socios, accionistas, directivos, administradores y representantes que se incorporen a la sociedad, así como aquellos que al momento de suscitarse la controversia hubiesen dejado de serlo".

Es recomendable que el convenio arbitral sea estipulado en el momento de fundación de la empresa, es decir, que sea incluido de manera simultánea a la elaboración del estatuto social pues de esta manera se estaría asegurando que a partir de entonces todo conflicto arbitrable no sería llevado a la vía judicial. Sin perjuicio de ello, su incorporación podría darse luego de la constitución de la empresa, a través de la modificación del estatuto social, pero el convenio arbitral sólo será oponible a los conflictos surgidos desde el momento en que se inscribe la modificación del estatuto social ante los Registros Públicos.

En lo que concierne al ámbito societario, el arbitraje no sólo sirve para la solución de los conflictos que pudiera tener la empresa con terceros en el desarrollo normal de sus acti- 
vidades, sino que también el arbitraje puede servir para solucionar los conflictos generados al interior de la empresa, siempre y cuando dichos conflictos versen sobre materias de libre disposición, tal y como lo estipula el artículo 2 de la referida Ley de Arbitraje.

\subsection{El arbitraje societario en Argentina}

En Argentina, las empresas familiares también constituyen un importante fenómeno empresarial, pues éstas representan alrededor del 75\% de las unidades económicas. Asimismo, constituyen una importante fuente de trabajo, ya que aportan el 70\% de los puestos de trabajo en la actividad privada y controlan el $95 \%$ de la comercialización. ${ }^{17}$

Sin embargo, en cuanto al arbitraje estatutario o arbitraje societario, la realidad, especialmente legislativa, es diferente. Es así que la Ley 19.550 de Sociedades Comerciales de la República Argentina guarda absoluto silencio en torno a la posibilidad de que los socios o, eventualmente, terceros, sometan los conflictos derivados de la dinámica societaria a arbitraje. Sin embargo, tampoco lo prohíbe en forma expresa, por lo que se entiende que el arbitraje estatutario, como mecanismo alterno de solución de controversias, es lícito, siempre y cuando se respeten los principios societarios indisponibles. ${ }^{18}$

Pese a que no se acoge expresamente la figura del arbitraje en la normativa societaria argentina, la Resolución General 7/05, Normas de la Inspección General de Justicia (IGJ), en su artículo 74 dispone: "Los estatutos de las sociedades por acciones y los contratos de sociedades de responsabilidad limitada, podrán incluir cláusulas arbitrales. (...)”, reafirmándose así la licitud de las cláusulas arbitrales en los estatutos sociales de las empresas argentinas. Sin embargo, al no señalarse qué tipo de arbitraje puede pactarse, los operadores jurídicos argentinos han entendido que la sociedad será libre de establecer el sistema de arbitraje que sea más conveniente según el tipo de conflicto que se suscite. ${ }^{19}$

Cabe destacar que el Anteproyecto de Reformas a la Ley de Sociedades Comerciales prevé, dentro de la posible nueva redacción del artículo 15, la posibilidad de incluir cláusulas arbitrales en los estatutos sociales tanto de sociedades cerradas como de sociedades que cotizan en la Bolsa de Valores.

De ello se desprende que tanto la doctrina como la legislación argentinas están en búsqueda de la implementación legal del arbitraje societario.

\subsection{El arbitraje societario en España}

Si bien en España hay una fuerte presencia de empresas familiares, cada día tienden a concentrarse y conformar importantes grupos empresariales; no obstante, la situación espa-

\footnotetext{
${ }^{17}$ Arrieta, Dolores. "Empresas familiares: cuando llegan los terceros”, obra citada, p. 68.

${ }^{18}$ Triolo, Ignacio. "Arbitraje societario en la República Argentina. Con especial referencia a las sociedades cerradas y a propósito de la normativa de la IGJ", p. 2, http://www.viziolitriolo.com.ar/pdf/arbitraje-societario-en-la-republica-argentina.pdf

${ }^{19}$ Triolo, Ignacio. "Arbitraje societario en la República Argentina. Con especial referencia a las sociedades cerradas y a propósito de la normativa de la IGJ", obra citada.
} 
ñola difiere ampliamente de la argentina en cuento a la regulación normativa del arbitraje societario.

Las instituciones europeas se han preocupado desde hace varios años por la continuidad de las pequeñas y medianas empresas, muchas de ellas de carácter familiar, con una regulación enfocada a su continuidad y en consecuencia a la mitigación de sus respectivos conflictos, tal como se aprecia en la Recomendación de la Comisión Europea No 94/1069/CE, de fecha 7 de diciembre de 1994.

En el ordenamiento jurídico español la principal referencia a estas formas de empresas se encuentra en la Ley 7/2003, Ley de Sociedad Limitada Nueva Empresa. Esta norma introdujo modificaciones en el Código de Comercio, la Ley de Sociedades de Responsabilidad Limitada, la Ley de Sociedades Anónimas y el Código Civil. Asimismo, en la segunda disposición final de la referida ley se establece que reglamentariamente se establecerán las condiciones de forma y otros requisitos para la publicidad de los protocolos familiares. ${ }^{20}$

Con relación al arbitraje societario, España cuenta hoy con un mejor respaldo normativo que en años anteriores. Este cambio positivo se dio través de la Ley 11/2011 (publicada el 20 de mayo del 2011), la cual modificó la Ley de Arbitraje (Ley 60/2003), especialmente lo concerniente al arbitraje societario, es así que en el nuevo artículo 11 bis de la Ley de Arbitraje, específicamente en su apartado primero, dispone, con carácter expreso, la posibilidad de que toda sociedad de capital pueda someter a arbitraje las controversias que se planteen en torno a ella, lo que debe hacerse estatutariamente con el voto favorable de una mayoría reforzada, concretamente dos tercios de las acciones o participaciones que representen el capital social. ${ }^{21}$

Asimismo, en el apartado tercero del artículo previamente citado se establece la facultad de los socios o administradores para poder someter a arbitraje la impugnación de acuerdos sociales, disponiendo para ello que deberá encomendarse la administración de dicho arbitraje, así como la designación del árbitro o árbitros, a una institución arbitral.

La nueva normativa española en materia de arbitraje, al establecer el marco legal para el arbitraje estatutario, ha contribuido a que el empleo de éste último sea más frecuente, al establecerse claramente las materias que pueden ser objeto de arbitraje y las condiciones que debe tener la respectiva cláusula arbitral, logrando finalmente con ello que la solución de los conflictos que pueden suscitarse al interior de la empresa sea más veloz y efectiva.

\footnotetext{
$\overline{20}$ Cfr. Domínguez Martínez, Pilar. "El arbitraje societario como medio de resolución de conflictos en la empresa familiar", obra citada, p. 4.

${ }^{21}$ Magdaleno, Antonia. "El arbitraje societario y su realidad normativa", p. 1, http://www.tagirona.org/pdfTribunal/Tri-06-022012-el-arbitraje-societario-y-su-realidad-normativa.pdf
} 


\section{CONCLUSIONES}

Los grupos de empresas familiares no son ajenos a los problemas de gobierno corporativo, típicos de otros conglomerados empresariales. Más aún, creemos que en ellos los conflictos intra-societarios clásicos suelen agravarse debido al factor "familia" que impregna toda la organización empresarial.

Es dentro de ese contexto que el arbitraje surge como un mecanismo alterno de solución de los conflictos, cuya peculiar naturaleza hace que sea imperativa la presencia de un tercero imparcial, con cualidades y capacidades especiales, que dirima de la forma más rápida y eficaz la controversia que afecta al grupo empresarial familiar.

Este arbitraje societario o estatutario es acogido en nuestra legislación, específicamente en la Ley de Arbitraje (Decreto Legislativo $N^{\circ}$ 1071) y en la Ley General de Sociedades (Ley No 26887). Sin embargo, su uso aún no es generalizado lo que implica que aún se siga recurriendo al Poder Judicial para resolver conflictos nacidos al interior de un grupo de empresas familiares, con los elevados costos que ello supone.

\section{COMO CITAR ESTE ARTÍCULO}

ECHAIZ MORENO, Daniel. El arbitraje en los grupos de empresas familiares. Revista de la Facultad de Ciencias Económicas - UNNE, Argentina. Volumen 22 Núm. 1, enero-junio 2019, ISSN 1668 - 6365. Págs. 29 - 41. DOI: http://dx.doi.org/10.30972/rfce.2213947

\section{CURRICULUM VITAE}

\section{Daniel Echaiz Moreno}

Doctorando en Derecho y Magíster en Derecho de la Empresa por la Pontificia Universidad Católica del Perú. Abogado summa cum laude por la Universidad de Lima. Socio fundador de ECHAIZ ABOGADOS. Ex Presidente de las Comisiones Consultivas de Derecho Empresarial y de Derecho Financiero y Bancario del Ilustre Colegio de Abogados de Lima. Catedrático de la Universidad Peruana de Ciencias Aplicadas (UPC), Universidad San Ignacio de Loyola, Universidad de Lima, Instituto de Gobierno y Gestión Pública de la Universidad de San Martín de Porres y Universidad Tecnológica del Perú (UTP). Miembro del staff de árbitros de los Centros de Arbitraje de la Cámara de Comercio de Lima, Pontificia Universidad Católica del Perú, Superintendencia Nacional de Salud, Cámara Peruana de la Construcción, Ministerio de Justicia y Derechos Humanos, Ministerio 
de Trabajo y Promoción del Empleo y Universidad Católica Santo Toribio de Mogrovejo (USAT). Miembro colegiado del Ilustre Colegio de Abogados de Lima. Miembro honorario del Ilustre Colegio de Abogados de Arequipa. Miembro asociado del Instituto Peruano de Derecho Mercantil. Investigador académico del Instituto Argentino de la Empresa Familiar. Miembro asociado de la Cámara Internacional de Conferencistas. Autor de 15 libros y más de 500 artículos especializados. Ha dictado más de 700 conferencias. Web page: www.echaiz.com daniel@echaiz.com 